\title{
Acquisition of Locative Utterances in Norwegian: Structure-building via Lexical Learning
}

\author{
Natalia MITROFANOVA $^{1 *}$ and Marit WESTERGAARD ${ }^{1,2}$ \\ ${ }^{1}$ UiT - The Arctic University of Norway, Norway and ${ }^{2}$ NTNU Norwegian University of Science \\ and Technology, Norway \\ *Corresponding author. E-mail: natalia.mitrofanova@uit.no
}

\section{ABSTRACT}

This paper focuses on the acquisition of locative prepositional phrases in L1 Norwegian. We report on two production experiments with children acquiring Norwegian as their first language and compare the results to similar experiments conducted with Russian children. The results of the experiments show that Norwegian children at age 2 regularly produce locative utterances lacking overt prepositions, with the rate of preposition omission decreasing significantly by age 3. Furthermore, our results suggest that phonologically strong and semantically unambiguous locative items appear earlier in Norwegian children's utterances than their phonologically weak and semantically ambiguous counterparts. This conclusion is confirmed by a corpus study. We argue that our results are best captured by the Underspecified P Hypothesis (UPH, Mitrofanova, 2017), which assumes that at early stages of grammatical development, the underlying structure of locative utterances is underspecified, with more complex functional representations emerging gradually based on the input. This approach predicts that the rate of acquisition in the domain of locative PPs should be influenced by the lexical properties of individual language-specific grammatical elements (such as frequency, morphological complexity, phonological salience, or semantic ambiguity). Our data from child Norwegian shows that this prediction is borne out. Specifically, the results of our study suggest that phonologically more salient and semantically unambiguous items are mastered earlier than their ambiguous and phonologically less salient counterparts, despite the higher frequency of the latter in the input. 


\section{INTRODUCTION}

In this article, we investigate the acquisition of locative constructions in Norwegian, presenting the results of three studies: two elicited production experiments of altogether 70 children in three age groups (2-, 3-, and 4-5-year-olds) and one corpus study (one child, age $1 ; 8-3 ; 3)$. We ask the following research questions: Do Norwegian children go through a stage of preposition $(\mathrm{P})$ omission, and what are the factors responsible for the order of acquisition of the various locative items found in the language - frequency, phonological weight, morphological complexity?

\section{ACQUISITION OF LOCATIVE STRUCTURES ACROSS LANGUAGES}

It has been argued that children's acquisition of linguistic structures related to spatial concepts passes through a series of stages. Numerous studies investigating the development of spatial cognition in children independently of their linguistic skills suggest that infants possess a conceptual representation of a number of spatial relationships already at the preverbal stage (cf. Gibson \& Spelke, 1983; Lakusta et al., 2007; Mandler, 1996, 2004; Piaget \& Inhelder, 1956; Pulverman et al., 2002; Wagner \& Carey, 2005 etc.). For instance, it has been shown that children discriminate between the concepts CONTAINMENT and SUPPORT already before the age of one (see Casasola \& Cohen, 2002; Quinn, 1994; Quinn et al., 1999). ${ }^{1}$

It has been suggested that children come to the language-learning task already preequipped with non-linguistic spatial concepts, and their task is to look for words that match them (Clark, 1973; Nelson, 1974; Piaget \& Inhelder, 1956; Slobin, 1973). Furthermore, it has been proposed that spatial concepts are hierarchically organized, and that the acquisition of spatial terms is determined by a universal hierarchy. Thus, Johnston

\footnotetext{
${ }^{1}$ In what follows, all-caps notation is used to refer to spatial concepts.
} 
and Slobin (1979) have argued that the notions CONTAINMENT, SUPPORT and OCCLUSION (cf. Piaget \& Inhelder, 1956) are the most salient and conceptually simple, while PROXIMITY and relations such as BETWEEN, FRONT and BACK are more complex and should therefore be acquired later than terms for more simple concepts. By and large, this conceptual hierarchy is supported by the acquisition order of locative terms in L1 English, Italian, Serbo-Croatian and Turkish (Johnston \& Slobin, 1979; see also Caselli et al., 1999).

Multiple studies have shown that prior to prepositions appearing in production, children produce locative utterances lacking overt Ps (Bowermann, 1973; Brown, 1973; Gagarina \& Voieikova, 2009; Leikin, 1998; Nicholas, 2011; Slobin, 1985). Examples of preposition omission in child English are provided in (1):

(a) draw paper

Intended: 'draw on paper'

(Tomasello, 1987: 85)

(b) mummy bathroom

Intended: 'mummy is in the bathroom'

(Felix, 1992:30).

In languages with overt morphological case marking, e.g., Russian, these utterances typically contain a noun in a case-marked form. For instance, Leikin (1998: 92) points out that "as a rule in the period $1 ; 10$ to $2 ; 4$ the prepositions are omitted in obligatory contexts including, in Russian, constructions with governed oblique cases", and specifically in locative contexts that require overt prepositions in adult Russian (e.g., stole 
table.PREP "on the table"). ${ }^{2}$

Logically, there are three possibilities regarding the state of children's underlying grammar at the stage of preposition omission. All these have been proposed in the literature, and we discuss them here in turn.

a) Absence of overt prepositions in production reflects absence of the corresponding functional category $\mathrm{P}$ in the children's underlying grammar;

b) The category $\mathrm{P}$ is present and adult-like, and preposition omission is a reflex of performance limitations;

c) The category $\mathrm{P}$ is present in children's underlying grammar, but is not yet targetlike.

Examining a corpus of an English-learning SLI child, Radford and Ramos (2001) propose a maturational account of preposition omission. They attribute the absence of prepositions in production to the lack of the corresponding category $\mathrm{P}$ in the child's underlying grammar. Specifically, they argue that in utterances involving preposition omission "the object is used without the transitive preposition which would be required to case-mark it in the adult grammar, suggesting that the object is a caseless noun expression which has no case-feature to be valued" (Radford \& Ramos, 2001: 50; cf. example 4). According to this approach, the functional category P matures in children's grammars in the course of development, and as a consequence, overt prepositions appear in production.

Nicholas (2011) proposed an alternative performance-based account of preposition omission at early stages of language development based on experimental data from child English and child Icelandic. Unlike English, Icelandic exhibits overt case marking on

\footnotetext{
2 PREP stands for prepositional case, which in Russian is assigned by locative prepositions $v$ 'in' and $n a$ 'on', as well as the preposition $o$ 'about'.
} 
nouns. In Nicholas' experiments, young Icelandic-learning children regularly produced nouns denoting location or direction of movement without prepositions, which are obligatory in adult Icelandic to encode spatial relations. However, Icelandic children consistently marked the nouns with dative or accusative case inflections to distinguish between locative vs directional contexts, respectively. Based on these data, Nicholas concludes that individual prepositions must be underlyingly present in child utterances, and that preposition omission is best attributed to performance limitations and not to a difference in grammatical competence.

Finally, Mitrofanova (2017) argues for the Underspecified P Hypothesis, according to which the category $\mathrm{P}$ in children's grammar at the stage of preposition omission is underspecified, and contains a Place head, which encodes a general locative meaning, but crucially no further functional projections and/or features (cf. Koopman, 2000; Svenonius, 2006, 2010 for a discussion of the underlying structure of locative PPs). A child's grammar at this stage lacks some or all individual locative prepositions, which are acquired gradually at later stages. Mitrofanova discusses the results of two experiments with Russian children. On the production side, the results show that utterances involving preposition omission in Russian do not conform to target-like case-assignment patterns. Specifically, in all locative utterances involving preposition omission children uniformly mark the nouns with prepositional case, independently of the specific case requirements of individual locative prepositions (e.g., stole table.PREP instead of na stole on table.PREP "on the table" or pod stolom under table.INSTR "under the table"), contra the performancebased approach. At the same time, children do not produce nouns in the default (nominative) case form, contra the predictions of the maturational approach. On the comprehension side, the results indicate that children who omit prepositions in production perform significantly worse on a pointing-out task than children from the same age group 
who reliably produce prepositions. The study concludes that these findings are consistent with the hypothesis that preposition omission reflects a non-target-like underlying structure in children's grammar. The grammar initially involves only one generalized (underspecified) locative category, while finer-grained distinctions within the locative domain emerge later. Mitrofanova (2017) assumes that the generalized Place head is phonologically null and universally assigns prepositional case to its complement noun, which accounts for the uniform pattern of case marking in Russian utterances involving preposition omission.

In this paper, we further explore the hypothesis that the transition from preposition omission to target-like use of prepositions reflects an underlying shift from a maximally generalized locative category to more specific locative structures. Specifically, our aim is to i) identify the acquisition stages of locative utterances in Norwegian, and ii) to investigate the influence of various lexical properties of individual locative items (such as frequency in the input, morphological complexity, phonological strength, semantic ambiguity) on the rate at which individual locative Ps are acquired. Norwegian presents an ideal testing ground for the relative importance of such factors, because the language has two distinct groups of locative items. The first group consists of phonologically weak, highly ambiguous, but at the same time morphologically simple and very frequent prepositions. The second group comprises less frequent and (for the most part) morphologically complex, but at the same time unambiguous and phonologically strong locative Ps. In the next section, we discuss the system of Norwegian locative items in more detail.

\section{THE SYSTEM OF LOCATIVE PPs IN NORWEGIAN}

This study focuses on four locative relations: containment (IN), horizontal support (ON), position lower on the vertical axis / partially covered by the ground object (UNDER), and 
position further away from the viewer on the horizontal axis / partially covered by the ground object (BEHIND). In this section we review how these relations can be expressed in Norwegian. We focus on the dialect spoken in Tromsø, as this is the location where the experiments were carried out. However, most of the features described here are relevant for other Norwegian dialects as well.

Norwegian locative items can be divided into four groups, as shown in (2):

(2) a) monosyllabic locative prepositions, which are typically unstressed and semantically ambiguous between locative and non-locative meanings (e.g., $i$ 'in', på 'on');

b) mono- or bisyllabic prepositions that can carry stress and are unambiguously locative in meaning (e.g., under 'under', bak 'behind' etc.);

c) complex forms consisting of so-called "short form locative particles" (SFLPs, cf. Taraldsen \& Svenonius, 2007) combined with basic locative Ps (e.g., inn-i into-in 'in', opp-på up-on 'on', opp-i up-in 'in', $u t-i$ out-in 'out in(to)';

d) complex forms containing basic locative Ps and so-called "long form locative particles" (LFLPs), which are themselves composed of a directional particle and a final -e (e.g., inn $+e$ i inside in 'in', opp $+e$ på up on 'up', ned $+e$ på down on 'down', $u t+e i$ out in 'out', etc.).

The four groups of locative items differ with respect to their syntactic properties. As observed by Taraldsen and Svenonius (2007), monosyllabic Ps from group (a) do not allow omission of the complement noun phrase and do not take her 'here' or der 'there' as complements, as shown in (3)-(4):

$\begin{array}{lllll}\text { *Det } & \text { sitter en } & \text { katt } & \text { på } \\ \text { it } & \text { sits } & \text { a } & \text { cat } & \text { on }\end{array}$

'There is a cat sitting on.' 
She played in there

'She played in there.'

On the other hand, complex prepositions involving SFLPs from group (c) can occur with a covert complement (a null pronominal element, or pro) and are also compatible with her/der 'here/there':

$\begin{array}{lllll}\text { Det } & \text { sitter } & \text { en } & \text { katt } & \text { oppå } \\ \text { it } & \text { sits } & \text { a } & \text { cat } & \text { up on }\end{array}$

'There is a cat sitting on top (of it).

(6)

$\begin{array}{llll}\text { Hun lekte } & \text { uti } & \text { der } \\ \text { she played } & \text { out-in } & \text { there }\end{array}$

'She played out there.'

According to Taraldsen and Svenonius (2007), the reason for the ungrammaticality of (3)-(4) is that group (a) prepositions (e.g., $i$ 'in', på 'on') impose restrictions on their complements, barring pro or her 'here' and der 'there' from this position. On the other hand, they account for the availability of such complements with group (c) prepositions by proposing the following underlying structure, see Fig.1:

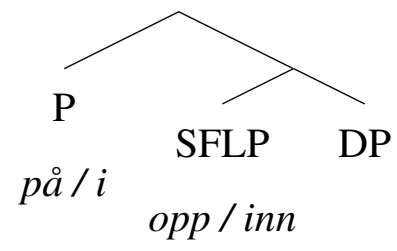

Fig. 1. Internal structure of Norwegian SFLP-P items

Under this analysis, SFLPs are taken to originate as part of the complement of simple prepositions. This means that in cases such as (6)-(7), pro and her/der 'here/there' merge 
as complements of the SFLP rather than the preposition itself. This plausibly makes these constructions exempt from the restrictions on such complements associated with simple Ps (cf. Fig. 2).

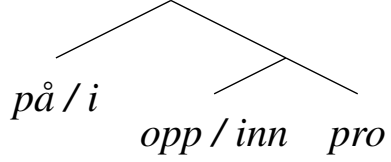

(a)

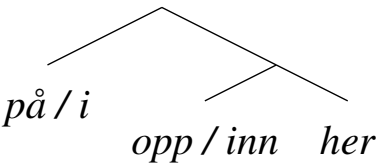

(b)

Fig. 2. The structure of Norwegian SFLP items lacking overt complements (a) and in combination with her 'here' (b)

Finally, Taraldsen and Svenonius (2007) attribute the surface order of the morphemes in group (c) items (SFLP-P) to leftward movement of the locative particle across the preposition, as illustrated in Fig. 3:

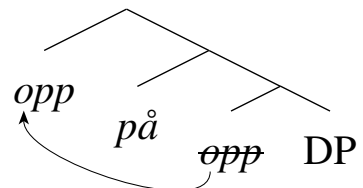

Fig. 3. Derivation of the SFLP-P morpheme order

Group (d) items (LFLP-P combinations such as inn+e $i$ 'in', opp $+e$ på 'up on') pattern with group (a) prepositions with respect to the discussed properties, i.e., they do not license covert complements and do not combine with her/der 'here/there':

$\begin{array}{lllllll}\text { *Det } & \text { sitter en } & \text { katt } & \text { oppe på/inne } & i \\ \text { it } & \text { sits a } & \text { cat } & & \\ \end{array}$

(8)

$\begin{array}{llllll}\text { *Katten } & \text { er } & \text { oppe } & \text { pa/inne } & i & \text { der } \\ \text { cat } & \text { is } & \text { up } & \text { on inside in there }\end{array}$

Taraldsen and Svenonius (2007) take this to indicate that LFLPs, in contrast to SFLPs, 
function as modifiers merging above $i$ 'in' and $p a ̊$ 'on'. This means that in ungrammatical constructions such as (7)-(8), pro and her/der 'here/there' must merge as direct complements of $i / p a ̊$, which is disallowed (see above).

Finally, group (b) prepositions (e.g., under 'under', bak 'behind') share many properties with group (c) items involving SFLPs. In appropriate contexts, they are also able to combine with covert complements and with her/der 'here/there', as illustrated in (9)-(10).

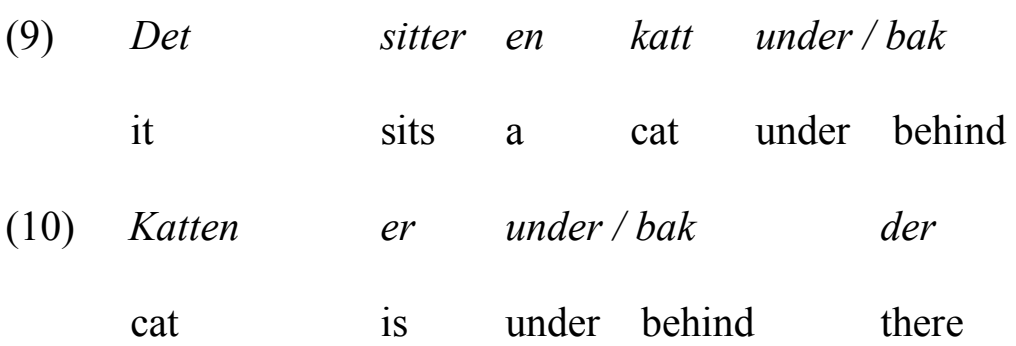

Taraldsen and Svenonius (2007) do not explicitly discuss this class of prepositions. Given the data in (9)-(10), one possible analysis is that class (b) prepositions have the same underlying structure as items involving SFLPs, but differ from them in terms of spell-out. While class (c) items involve two separate morphemes spelling out the relevant functional heads (SFLP and P), class (b) prepositions lexicalize both functional heads with a single morpheme (cf. Caha, 2009; Svenonius, 2012 on the model of spell-out which allows for a single morpheme to lexicalize a sequence of syntactic heads).

Summing up, group (b) and group (c) items pattern alike with respect to the availability of covert ground complements and her/der 'here/there'. They also share certain phonological and semantic features: they are able to carry stress and are unambiguously locative in meaning. In this paper, we refer to group (b) and (c) locative items as strong Ps, in contrast to group (a) prepositions, which we refer to as weak Ps. Group (d) items involving LPLFs will not be considered in this study, since their production rate in the responses of our participants was negligible. The properties of 
Norwegian strong and weak Ps are summarized in Table 1.

TABLE 1. Properties of weak and strong classes of Norwegian locative Ps

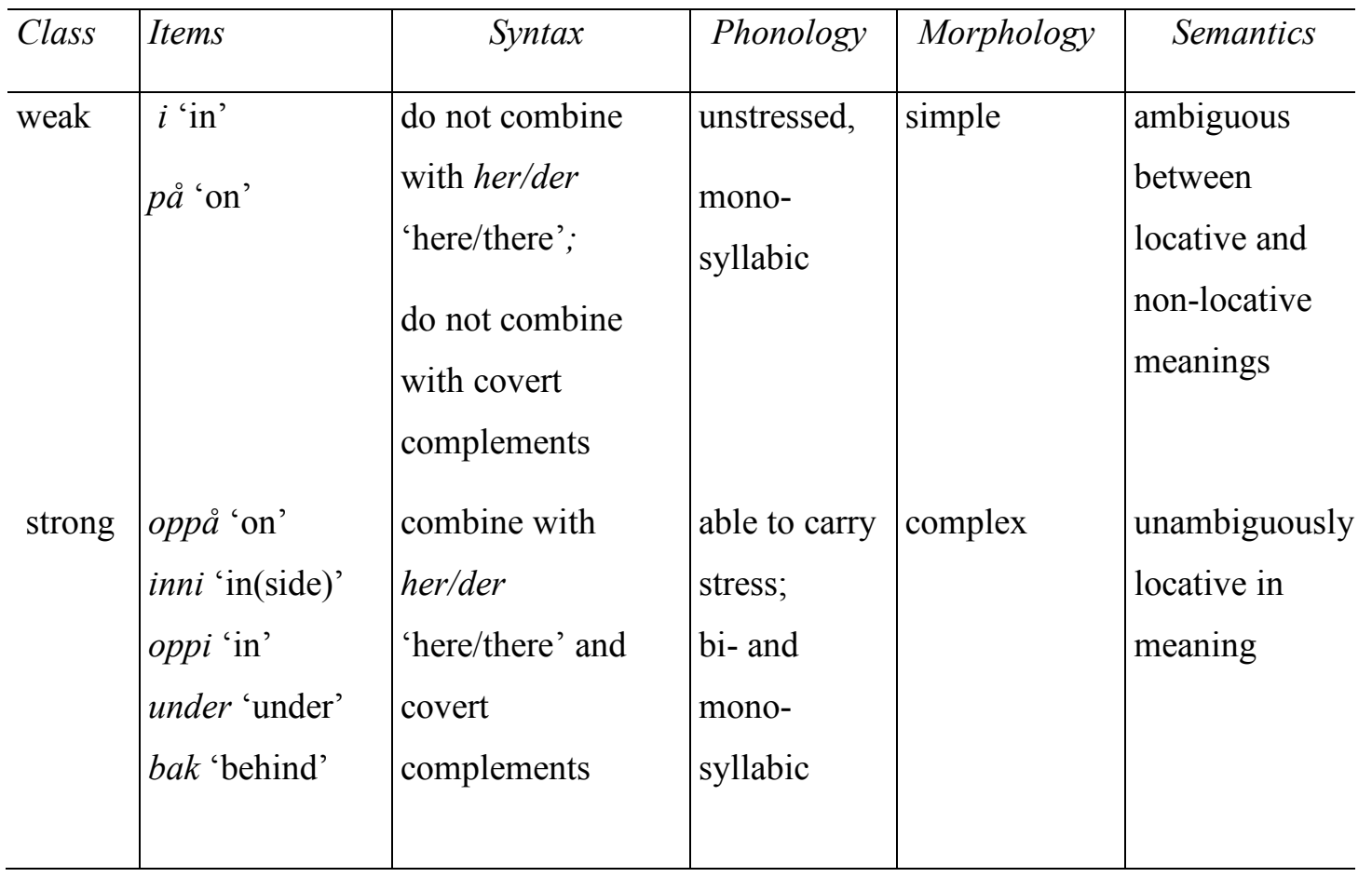

\section{RESEARCH QUESTIONS AND PREDICTIONS}

The Underspecified P stage

As outlined above, Russian, English and Icelandic children have been shown to produce a considerable number of utterances involving preposition omission at early stages of language development. In this study, we investigate the acquisition of Norwegian locative utterances in light of this previous research. If the Underspecified P(reposition) stage (see Mitrofanova, 2017) is indeed universal, and given that Norwegian lacks a morphological item with a generalized locative meaning, we expect Norwegian children to also omit prepositions at the earliest stages, with the rate of preposition omission decreasing significantly by the age of three. Furthermore, according to the UPH, first language acquisition is incremental and input-driven, i.e., the development of target-like locative structures is the result of the acquisition of language-specific spatial items. Thus, our 
second research question concerns the role of lexical properties in the acquisition of language-specific locative items.

\section{The role of lexical factors}

Given the system of locative prepositions in Norwegian, we are able to test the relative importance of different factors for the rate of acquisition of locative items. As discussed above, the developmental order in the acquisition of locative terms cross-linguistically is often taken to reflect a hierarchy of conceptual complexity. Furthermore, Johnston and Slobin (1979) have argued that lexical diversity may slow down the acquisition process. For example, English has numerous ways of encoding proximity (near, next to, beside, by, close to, etc.), while Turkish has only one term (yaninda). Johnston and Slobin argue that lexical diversity is responsible for the delayed emergence of English proximity prepositions as compared to Turkish. Similarly, morphological complexity and semantic ambiguity of prepositions are predicted to slow down the acquisition of locative terms (see Johnston \& Slobin, 1979:531; Slobin, 1985). Another factor that has been argued to influence the acquisition of functional items is input frequency, with highly frequent items being generally acquired earlier (Ambridge et al., 2015; Gülzow \& Gagarina, 2007; Lieven, 2010; Theakston et al., 2004; see however Ambridge, 2010 on the uncertainties connected to estimating frequency based on various types of corpora). Furthermore, acoustic/phonological/prosodic saliency (such as e.g., the ability to carry stress) has been found to play a facilitative role in acquisition (Gleitman \& Wanner, 1982; Slobin, 1985; see Kern, Gayraud \& Chenu, 2014 for an overview).

Based on this previous research, we investigate the influence of six potential factors on the acquisition of locative Ps in Norwegian: conceptual hierarchy, frequency, morphological complexity, phonological strength, semantic ambiguity and lexical diversity. Johnston and Slobin's (1979) conceptual hierarchy predicts that terms for 
simpler concepts, i.e., IN, ON and UNDER, will be acquired earlier than terms for more complex concepts, i.e., BEHIND, irrespective of their weak/strong status. In other words, strong and weak versions of prepositions denoting IN and $\mathrm{ON}$ in Norwegian would be expected to appear approximately at the same time. On the other hand, if overall frequency is the central factor, we expect weak preposition, i.e., $i$ 'in' and $p a^{\circ}$ 'on', to be acquired earlier than their strong counterparts inni 'in', oppi 'in' and oppå 'on', since weak prepositions are substantially more frequent in the input than strong Ps (as we discuss below, weak prepositions denoting IN and $\mathrm{ON}$ are at least 8 times more frequent in child-directed speech than their strong counterparts). A similar result is expected if morphological complexity is the key factor: weak prepositions expressing the relations IN and ON are predicted to appear earlier in production than their morphologically complex strong counterparts. Finally, if the rate of acquisition is mainly influenced by semantic ambiguity and/or phonological strength, it is predicted that strong prepositional items should emerge earlier than weak Ps. These predictions are summarized in Table 2. Furthermore, we can explore the role of lexical diversity by comparing the acquisition of locative Ps in Norwegian with Russian, since Norwegian has multiple ways of expressing the relations IN and $\mathrm{ON}$ ( $i$ 'in', oppi 'in', inni 'in(side)' and på 'on', oppa 'on'), while Russian employs only one locative preposition for each of these relations ( $v$ 'in' and $n a$ 'on'). If lexical diversity is an important factor in acquisition, we expect locative items expressing IN and ON to appear earlier in the speech of Russian children than in the speech of their Norwegian peers, see Table 2. 
TABLE 2. Predictions for the acquisition of Norwegian locative items

\begin{tabular}{l|l}
\hline Factor & Prediction \\
\hline Conceptual hierarchy & IN, ON, UNDER > BEHIND, strong=weak \\
Frequency & weak > strong \\
Morphological complexity & weak > strong (for IN and ON) \\
Phonological strength & strong > weak \\
Semantic ambiguity & strong > weak \\
Lexical diversity & Russian > Norwegian \\
\hline
\end{tabular}

To sum up, the research questions that we ask with respect to Norwegian are the following:

I) Do Norwegian children omit preposition at the earliest stages of acquisition at non-negligible rates?

II) Is the rate of acquisition influenced by the lexical properties of the locative items? If so, what is the relative contribution of the following factors:

a) conceptual hierarchy

b) overall frequency

c) morphological complexity

d) semantic ambiguity

e) phonological strength

f) lexical diversity

To answer these questions, we conducted an elicited production study (Study 1) with a group of Norwegian children aged 2-5. The elicited production study was modeled on the experiment with Russian children presented in Mitrofanova (2017). Additionally, 
a subset of children from Experiment 1 participated in a small-scale follow-up study (Puzzle-board task). The goal of this task was to assess the influence of pragmatic context on children's production. We also performed an analysis of longitudinal corpus data (Study 2) in order to investigate the acquisition of strong and weak prepositions over time. We present these studies in the next section.

\section{STUDY 1: ELICITED PRODUCTION}

METHOD

\section{Participants}

A group of monolingual Norwegian-speaking children aged 2-5 years were recruited from 10 daycare centers in Tromsø $(\mathrm{n}=77)$. Seven participants did not complete the experiment due to shyness, disinterest, or insufficient linguistic proficiency (lacking vocabulary for the objects involved in the experiment). The breakdown of the remaining 70 participants by age is given in Table 3. All children were identified by their teachers as typicallydeveloping. In addition, we tested a group of 13 monolingual adult controls.

TABLE 3. Participants' demographics by age group, Experiment I

\begin{tabular}{ccccc}
\hline Age group & $N$ & $n$ boys & Age range & Mean age \\
\hline 2-year-olds & 22 & 6 & $2 ; 2$ to $2 ; 11$ & $2 ; 7$ \\
3-year-olds & 27 & 9 & $3 ; 0$ to $3 ; 11$ & $3 ; 6$ \\
4-5-year-olds & 21 & 11 & $4 ; 0$ to $5 ; 11$ & $4 ; 11$ \\
adults & 13 & 3 & 23 to 35 & 27 \\
\hline
\end{tabular}

\section{Design and Materials}

The experiment was conducted as a language game where the children were asked to describe pictures from a picture book to the experimenter. An experimental trial went as follows: First, the children were shown pictures of isolated figure and ground objects (e.g., 
a teddy bear and a boat, respectively) and asked to name them. ${ }^{3}$ Then they were shown a series of pictures, where each picture illustrated one of the four types of spatial scenes: containment (IN), horizontal support $(\mathrm{ON})$, position lower on the vertical axis / partially covered by the ground object (UNDER), and position further away from the viewer on the horizontal axis / partially covered by the ground object (BEHIND).

The game was modeled as a dialogue between the research assistant and the child. The research assistant showed the child pictures and asked two types of questions: What is that? (for pictures representing isolated figure and ground objects) or Where is $X$ ? (for pictures representing spatial scenes). The set of stimuli included seven pictures with isolated figure objects (a teddy bear, a ball, a cat, a dog, a mouse, a spade, and a book), seven pictures of ground objects (a boat, a toy truck, a box, a chair, a table, a cupboard, and a sofa), and 20 experimental pictures, each illustrating one of the four possible spatial configurations (IN, ON, UNDER, and BEHIND). Overall, for each participant, each of the four spatial configurations functioned as the target five times, in combination with different ground objects. The spatial scenes were presented in a pseudo-randomized order. The experiment lasted approximately 5-10 minutes.

\section{Procedure}

The children were tested one by one in a separate room in the daycare center. The child sat next to a research assistant who was a native speaker of Norwegian. A laptop was placed on a table in front of the child and was used to make video and audio recordings of the responses. The research assistant showed the child a series of pictures from the picture book and asked her to describe each picture. The following represents a model procedure:

\footnotetext{
${ }^{3} \mathrm{We}$ follow Talmy (2000) in using the term figure for the object whose location is specified, and ground for the reference object with respect to which the figure is being located.
} 
a) The child looked at a picture of a figure object, e.g., a teddy bear (Fig. 4A), and was asked to name it.

Experimenter:

$\begin{array}{llll}\text { Ka } & \text { det } & \text { her? } \\ \text { what is } & \text { this here }\end{array}$

'What's this?'

Child's expected answer:

En bamse

a teddy bear

b) Next, the child was shown a picture of a ground object, e.g., a boat (Fig. 4B), and was also asked to name it.

Experimenter:

Veldig bra! Og den her da?

very good! and this here then?

'Good job! And what's this then?'

Expected answer:

En båt.

A boat

c) Then the child was shown a picture of the figure object located in, on, under, or behind the ground object, e.g., a teddy bear in a boat (Fig. 4C), a teddy bear on top of a boat (Fig. 4D), a teddy bear under a boat (Fig. 4E), or a teddy bear behind a boat (Fig. 4F). The experimenter then asked the following question:

Experimenter:

Kor e bamsen nu da?
where is teddy bear now then?
Where's the teddy bear now?

The child's expected answer (Fig. 4C): $\quad$ Oppi $/ i \quad$ båten .

In boat.DEF

The child's expected answer (Fig. 4D): Oppå / på båten

On boat.DEF

The child's expected answer (Fig. 4E): Under båten.

Under boat.DEF 
The child's expected answer (Fig. 4F): Bak båten

Behind boat.DEF

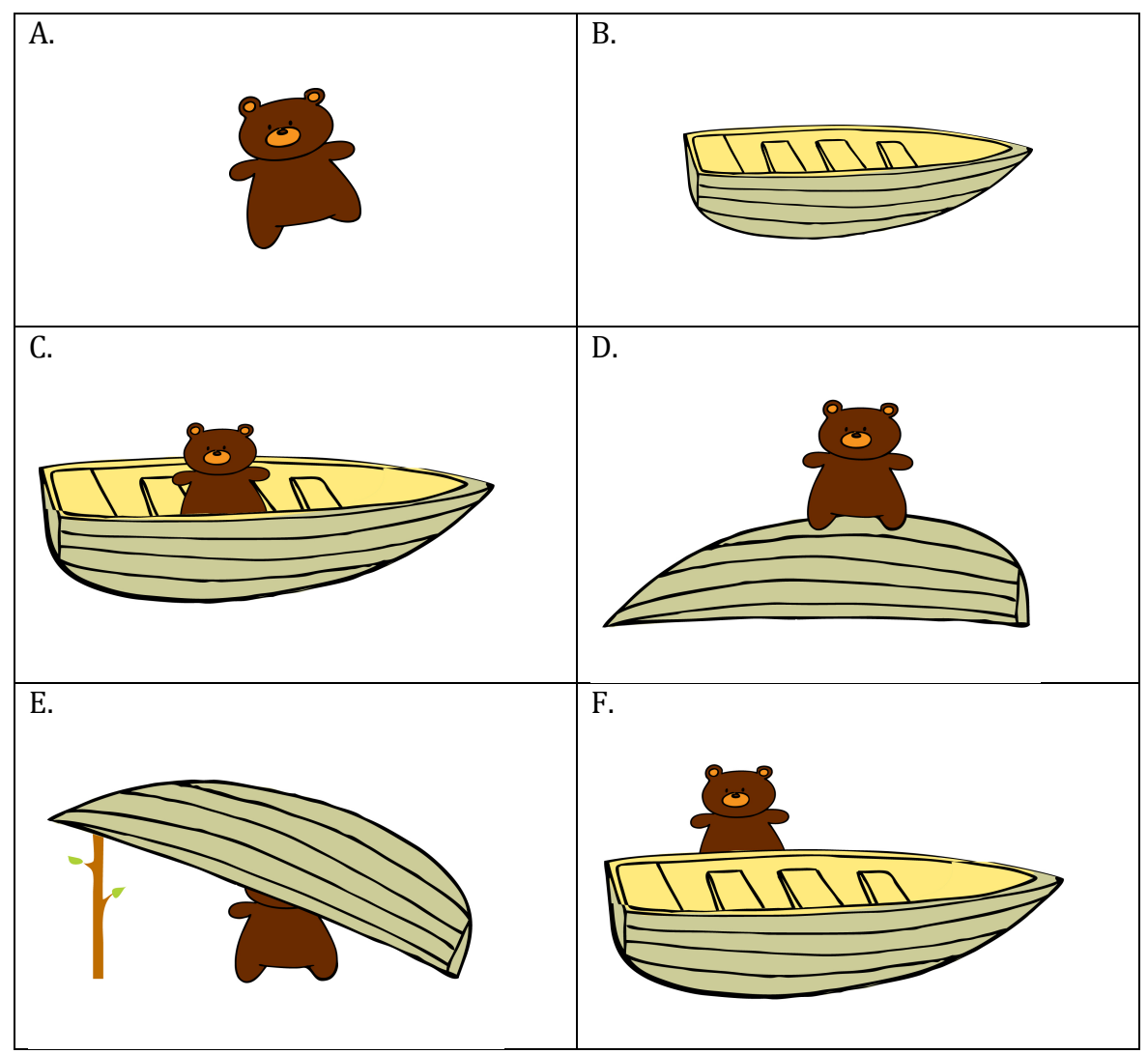

Fig. 4: Examples of experimental stimuli: isolated figure (A) and ground (B) objects, and two locative configurations (C-D).

RESULTS

The responses given by the participants were divided into the following five categories:

a) Utterances lacking locative prepositions (coded as "bare N" responses), e.g., ligg stolen 'is lying chair.DEF' or musa bordet 'mouse.DEF table.DEF' etc.

b) Utterances containing a strong preposition without an overt complement (coded as "bare strong P") e.g., den e under 'it is under (it)', bamsen e oppi 'the bear is 
up.on (it)', etc.

c) Utterances containing a strong preposition followed by der 'there' (coded as "strong $\mathrm{P}+$ der") e.g., under der 'under there', oppi der 'up.on there', etc.

d) Utterances containing full locative PPs involving weak prepositions $i$ 'in' and $p a$ 'on' (coded as "weak P + N"), e.g., på båten 'on the boat', i skapet 'in the cupboard' etc.

e) Utterances containing full locative PPs involving strong prepositions (coded as “strong P + N"), e.g., oppå båten 'on the boat', under sofaen 'under the sofa' etc.

The proportions of different types of responses across the age groups are presented in Figure 5. The figure shows that the preferred response pattern in all age groups is "strong $\mathrm{P}+\mathrm{N}$ ". The proportion of this pattern increases considerably between the two first age groups and then sees a more gradual development. "Bare N" responses only appear in the two youngest age groups (only marginally in the group of three-year-olds), while the "strong $\mathrm{P}+$ der" pattern is attested in all three groups of children (but only minimally in the group of four-to-five-year-olds). Perhaps surprisingly, the "weak $\mathrm{P}+\mathrm{N}$ " pattern is a relatively infrequent choice in all groups. At the same time, "bare strong $\mathrm{P}$ " is the second most favored pattern among all the children, but is only rarely attested in the responses of adult controls. There were practically no responses (only one participant produced one such utterance) consisting of bare weak prepositions (e.g., $i$ 'in' or på 'on'). There were no responses containing a weak $\mathrm{P}$ in combination with a long-form locative particle (e.g., inne $i$ 'in' or oppe på ‘on') without a complement DP (which would be ungrammatical in adult Norwegian), not even in utterances produced by the youngest children. 


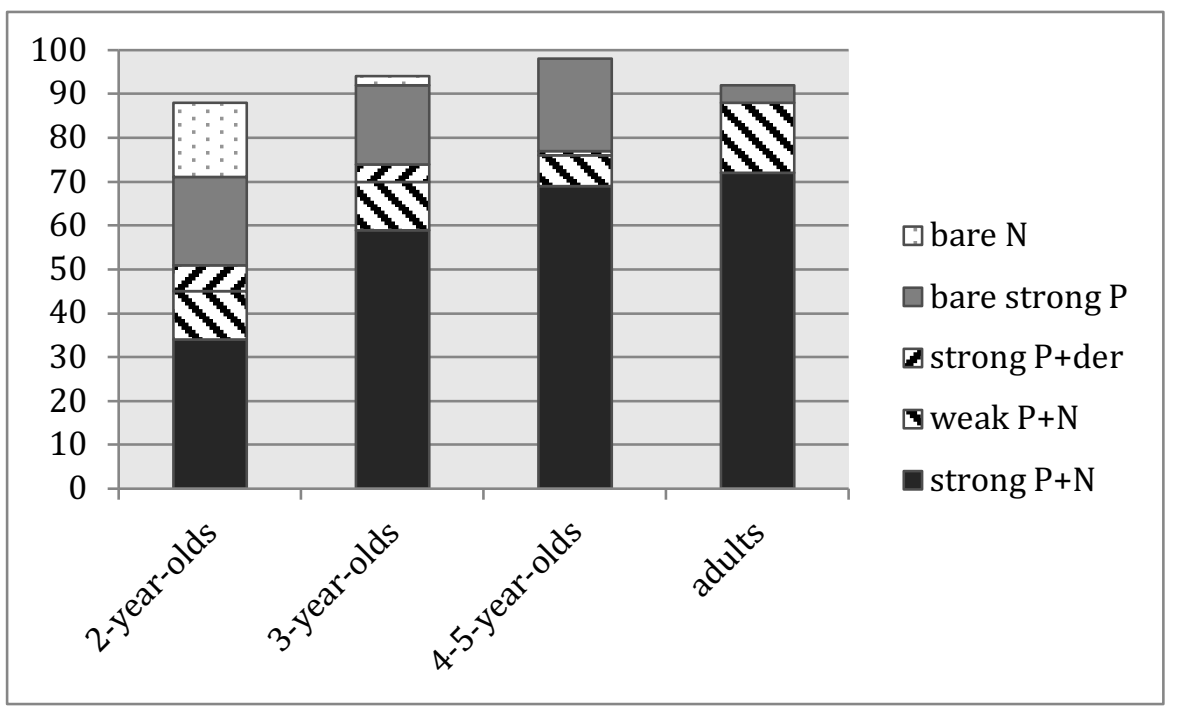

Fig. 5: The distribution of response types by age group (in \%)

The experiment revealed that the rate of preposition omission decreases rapidly between two and three years of age: from $17 \%$ in the responses of the two-year-olds to only $2 \%$ in the responses of the three-year-olds. Four- and five-year-old children and adults did not produce any utterances involving preposition omission. The rate of omission fluctuated slightly, the mean being $20 \%$ in IN and ON configurations and $13 \%$ in UNDER and BEHIND contexts. Our data are nested within participants and items, which is why we used a linear mixed model analysis, which has been argued to capture such data better than e.g., ANOVAs (see Jaeger, 2008; Quené \& van der Bergh, 2008). To analyze the differences between the groups, we fit a binomial generalized linear mixed effects model estimating the probability of bare $\mathrm{N}$ locative utterances in the responses of two- and three-year-olds based on the interaction of two predictors: AGE GROUP (twoyear olds versus three-year olds) and CONFIGURATION (IN/ON versus UNDER/BEHIND). Participants and Items were included as random effects. The statistical analysis was performed using the library lme4 (Bates et al., 2014) of the statistics software R version 3.2.1 (release 2015-06-18). The results showed a significant main effect of AGE GROUP: the proportion of bare $\mathrm{N}$ responses decreased significantly from the two-year-olds to the 
three-year-olds $(\beta=-4.62, S E=1.21, p<0.001)$, but no significant effect of CONFIGURATION was observed. This suggests that two-year-olds were significantly more likely to omit prepositions than three-year-olds, irrespective of the spatial configuration (see the details of the model in Table 8 in the Appendix).

We fit a generalized linear mixed effect model to estimate the effect of the interaction of AGE GROUP and CONFIGURATION on the production of Full PPs. Participants and Items were included as random effects. The proportion of full PPs (containing either strong or weak Ps) increases significantly in the responses of the three-year-olds as compared to two-year-olds: $45 \%$ for the two-year-olds and $70 \%$ for the three-year-olds $(\beta=2.00$, $S E=0.44, p<0.001)$. The proportion of full PPs continues to grow gradually in the responses of four- and five-year-olds (76\%) and reaches $88 \%$ in the adult responses. Twoyear-olds produced significantly fewer full PPs than all other groups (see the details of the analysis in Table 9 in the Appendix).

A somewhat unexpected result was that all groups of children produced a large number of utterances containing bare strong prepositions without complement DPs. Adults produced such utterances at a significantly lower rate: $4 \%$ as compared to $20 \%$ in the two-year-olds, $18 \%$ in the three-year-olds, and $21 \%$ in the four-to-five-year-olds. We fit a generalized linear mixed effect model to estimate the effect of the interaction of AGE GROUP and CONFIGURATION on the production of bare strong Ps. Participants and Items were included as random effects. The adult group was significantly different from all other groups, while there were no significant differences between the three child groups (see Table 9 in the Appendix for details).

Recall that bare strong Ps, though being a less-preferred option, are not ungrammatical in adult Norwegian. Recall also that in Experiment 1, the experimenter and the child viewed the picture book together, and thus the experimenter had visual 
access to both the figure and ground objects of the spatial scenes described by the child. We hypothesized that the high rate of bare strong P utterances in children's responses may be linked to children's tendency to be more economical in production and omit items that can easily be retrieved from the context (cf. Philips 2010, Westergaard 2008). If this is the case, we predicted that change in the pragmatic context would influence the rate of children's bare strong P responses. To test this, we conducted a small-scale follow-up experiment, where the children were encouraged to describe pictures on a puzzle board to an adult who could not see the picture that the child was describing. The puzzle board had eight cut-out windows containing laminated colored pictures. The experimenter had a set of eight puzzle pieces with pictures matching the ones on the puzzle board. The child's task was to ask for a matching picture from the experimenter's set and put it in the corresponding cut-out window on the puzzle board (see Eisenbeiss, 2009, 2010 for a discussion of this elicitation technique). A subset of the children ( $N=17$, see Table 10 in the Appendix) who participated in Experiment 1 were recruited for this follow-up task. We compared their responses in Experiment 1 (the picture book task) and the follow-up experiment (the puzzle board task) and estimated the effect of the task on the probability of bare $\mathrm{P}$ responses. The results showed a significant main effect of the task $(\beta=-1.48$, $S E=0.68, p<0.05)$, i.e., the participants were more likely to produce bare strong $\mathrm{P}$ utterances in the task where the interlocutor was sitting next to the child and looking at the same picture (Experiment 1) than the task where the interlocutor was not able to see the picture that was being described (Puzzle-board task), see Table 11 in the Appendix. This indicates that the rate of bare strong Ps in child speech is dependent on the pragmatic context. Specifically, the children omitted ground DPs significantly more often when the ground object was visually accessible to the interlocutor and thus could be easily reconstructed from the context. 
Let us now consider the question of the relative order in which the two different groups of prepositions, strong Ps and weak Ps, appear in production. Indirect evidence that the production of strong prepositions precedes that of their weak counterparts comes from the response patterns of the youngest children, cf. Table 4.

\section{TABLE 4}

Types of responses given by two-year-old participants, Experiment $1(n=23)$

\begin{tabular}{cccc}
\hline Nof participants & bare $N$ & Strong $P S$ & Weak Ps \\
\hline 2 & yes & no & no \\
8 & yes & yes & no \\
5 & yes & yes & yes \\
1 & yes & no & yes \\
2 & no & yes & no \\
5 & no & yes & yes \\
\hline
\end{tabular}

As is evident from the table, ten out of the 22 participants in this group used strong prepositions and did not use weak prepositions, while only one participant used weak prepositions, but did not use strong prepositions. This participant produced only one utterance with a weak preposition and none with strong prepositions. Thus, we suspect that this unusual pattern might be due to the extremely low number of responses given by this participant (only 7 out of 22 responses in total). Overall, we interpret this finding as indicating that strong prepositions tend to appear earlier in production as compared to their weak counterparts, despite the very high overall frequency of weak prepositions in the input. In the next section, we describe a corpus study which we conducted in order to further test this conclusion. 
STUDY 2: CORPUS ANALYSIS

We analysed a corpus of 27 files of spontaneous conversations with one typically developing child (Ina) acquiring the Tromsø dialect of Norwegian. The corpus spans the period from 1;8 to 3;3 years of age (see Anderssen, 2005 for further information about the corpus). We analysed utterances produced by the child (INA) and compared them to the child-directed speech (CDS) in the same corpus. The CDS comprised utterances produced by the investigator, the child's parents and in the last file, the child's grandmother. Table 5 summarizes the details of the corpus.

TABLE 5. Overview of the Ina corpus (Anderssen, 2005)

\begin{tabular}{llll}
\hline & Age in months & $\begin{array}{l}\text { No. of words per } \\
\text { file INA }\end{array}$ & $\begin{array}{l}\text { No. of words per } \\
\text { file CDS }\end{array}$ \\
\hline Range & $20-39$ & $475-4795$ & $1152-7815$ \\
Mean & 29 & 2078 & 4556 \\
Total & & 56105 & 123001 \\
\hline
\end{tabular}

We counted the occurrences of strong items (oppi 'in', inni 'in(side)', oppå 'on', under 'under', and bak 'behind') and their weak counterparts ( $i$ 'in', $p a^{\circ}$ 'on') for both the child and the adults. For the child, we excluded uses that were a direct repetition of an adult's or the child's own utterance (up to two utterances before the actual production). Table 6 summarizes the time of first occurrence and overall frequency of individual items throughout the corpus for the child and the adults. 
TABLE 6. First occurrence and overall frequency of individual Ps in the corpus: INA and $C D S$

\begin{tabular}{lllll}
\hline Item & First occurrence & $\begin{array}{l}\text { Frequency } \\
\text { INA }\end{array}$ & $\begin{array}{l}\text { First } \\
\text { occurrence CDS }\end{array}$ & $\begin{array}{l}\text { Frequency } \\
\text { CDS }\end{array}$ \\
\hline$i$ & $1 N A$ & 288 & $1 ; 8(1)$ & 1694 \\
på & $1 ; 10(2)^{*}$ & 494 & $1 ; 8(1)$ & 1876 \\
oppi & $1 ; 10(2)$ & 83 & $1 ; 8(1)$ & 164 \\
inni & $2 ; 1(6)$ & 109 & $1 ; 10(2)$ & 144 \\
oppå & $1 ; 8(1)$ & 76 & $1 ; 8(1)$ & 87 \\
under & $1 ; 11(4)$ & 32 & $1 ; 10(2)$ & 91 \\
bak & $2 ; 6(14)$ & 5 & $1 ; 8(1)$ & 38
\end{tabular}

*Child's Age (File No.)

As Table 6 shows, the child's first use for all items except inni 'in(side)' and bak 'behind' occurs before age 2 (the first occurrence of inni 'in(side)' is at 2;1, and the first occurrence of bak 'behind' is at 2;6). Furthermore, the overall frequency of weak Ps is at least 8 times higher than that of their strong counterparts in child-directed speech. The frequency of strong Ps in child and adult speech is comparable, while the frequency of weak Ps is much lower in the child's speech as compared to that of the adults.

Given that the files in the corpus are of different lengths, we calculated the proportion of Ps relative to the number of words produced per file for the child and the adults (coded as INA and CDS, respectively). The change in the proportions over the corpus is illustrated in Figures $6-7$. Note that Ina's proportion of strong Ps is at an equal or higher rate than that of the adults, while her proportion of weak Ps is at a lower rate and exhibits a gradual increase throughout the corpus. 


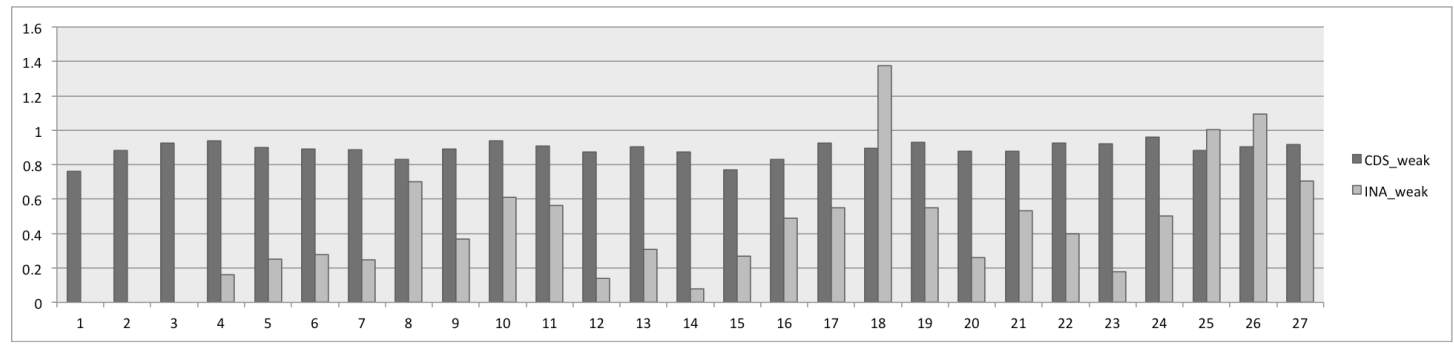

Fig.6. Proportion of weak prepositions per 100 words over the 27 recordings

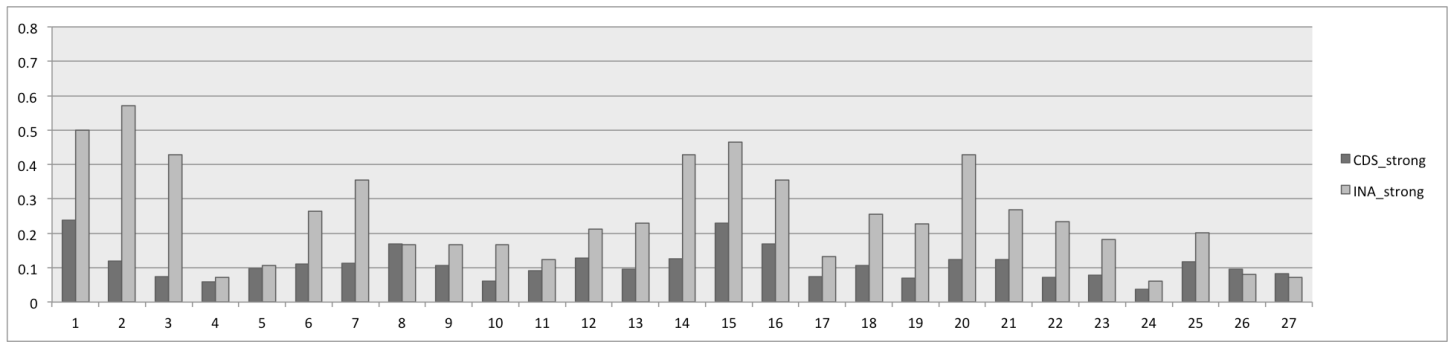

Fig. 7. Proportion of strong prepositions per 100 words over the 27 recordings

In order to establish whether the difference between the child and the adults is significant, we fit a generalized linear (Poisson) model where the number of uses was predicted given the interaction of two explanatory variables: SPEAKER (child vs adult) and AGE (in months). The log of number of words per file for the child and the adults, respectively, was used as offset (the generalized linear Poisson model is commonly used when the denominators for the two groups vary, e.g., the child and the adults produced a different amount of words per file; see Gelman \& Hill 2006). The results of the analysis show that there was no significant difference between the child and the adults with respect to the use of strong Ps. There was no effect of age either: the child's use of strong Ps did not change significantly between $1 ; 8$ and $3 ; 3$ years. We conclude that the child was not significantly different from the adults with respect to the use of strong Ps throughout the corpus (see Table 12 in the Appendix for details of the model).

In contrast, the child was not target-like with respect to the use of weak prepositions: the adults used significantly more weak Ps than the child $(\beta=2.29, S E=0.26, p<0.001)$. 
There was also a significant positive correlation of the child's weak $\mathrm{P}$ production and age, as the proportion of weak Ps increased significantly from $1 ; 8$ to $3 ; 3$ years $(\beta=0.06$, $S E=0.01, p<0.001)$. The use of weak Ps by the adults did not change throughout the corpus. The details are summarized in Table 12 in the Appendix.

As pointed out above, weak prepositions are ambiguous between locative and nonlocative uses. This means that the low overall rate of weak prepositions in Ina's speech does not necessarily imply that she is non-adult-like with respect to the locative uses of these prepositions. Indeed, it could be the case that the difference observed between Ina and the adults is due to the child underusing weak prepositions in non-locative contexts, while the proportion of locative uses is target-like. To test this, we manually classified all of the child's uses of weak prepositions throughout the corpus as either locative or nonlocative. We counted the cases where the complement of the preposition indicates a location (e.g., i barnehagen 'in daycare', $i$ stua 'in the living room', pa bordet 'on the table', etc.) as locative. In contrast, we categorized cases where the preposition is selected by the verb in verb-P constructions (e.g., se på 'look at', kle på 'put on (clothes)', glad $i$ 'fond of', etc.) as non-locative. We then ran the same type of statistical analysis (generalized linear Poisson model) to estimate whether there was an effect of age for locative and non-locative uses of weak Ps separately. The results show that the proportion of both locative and non-locative uses of weak Ps increased significantly with age $(\beta=0.08, S E=0.01, p<0.001$ for locative uses, and $\beta=0.05, S E=0.01, p<0.001$ for nonlocative uses; see Table 13 in the Appendix). This suggests that Ina is still in the process of acquiring weak Ps, both in their locative and non-locative uses, in the time span covered by the corpus. We further compared only the locative uses of weak and strong Ps. As Figure 8 clearly illustrates, the use of strong Ps does not change significantly throughout the corpus, while the use of weak Ps increases significantly with age. 


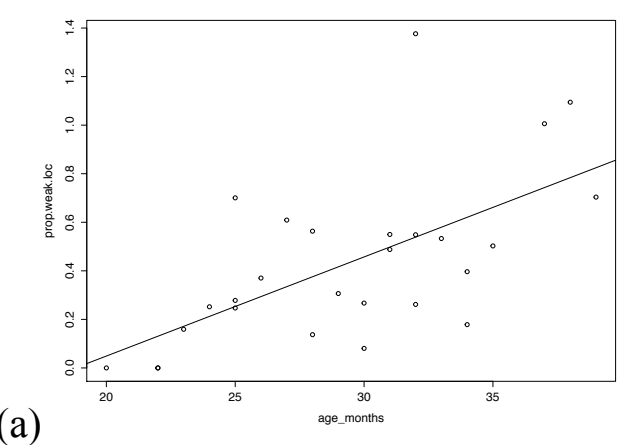

(b)

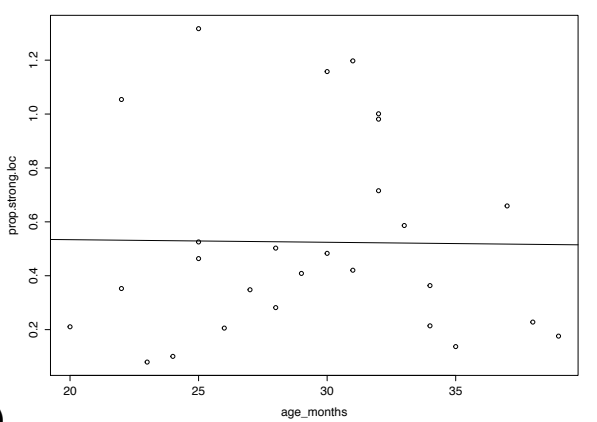

Fig. 8. Regression lines representing a change in proportion of (a) weak and (b) strong locative prepositions per 100 words over time (age_in_months) for Ina.

To sum up, the results of our corpus analysis show that the child is not significantly different from the adults with respect to the use of strong Ps. Furthermore, the proportion of strong Ps does not change significantly throughout the corpus. At the same time, she uses significantly fewer weak Ps than the adults, and the use of weak Ps increases significantly towards the later files of the corpus. We conclude that the child's use of strong Ps becomes adult-like earlier than that of weak Ps and that strong locative prepositions present fewer difficulties for children in the course of first language acquisition. We return to these results in the Discussion.

\section{DISCUSSION}

Our predictions with respect to the acquisition of locative Ps in Norwegian were the following:

1) If the Underspecified P stage is universal, we expect Norwegian children to omit prepositions at the earliest stages.

2) Acquisition is expected to be input-driven and dependent on the lexical properties of locative items.

In connection with Prediction 2, we examined the role of the following lexical factors: conceptual hierarchy, overall frequency, morphological complexity, semantic ambiguity, 
phonological strength, and lexical diversity.

Prediction 1 was borne out by the results of Study 1 . The highest rate of preposition omission was observed in the responses of two-year-old children and decreased dramatically in the responses of the three-year-olds. This is similar to the pattern observed for Russian children in Mitrofanova (2017), where 32\% of the responses given by twoyear-olds in a similar elicited production experiment involved preposition omission. The pattern observed for Norwegian and Russian two-year-olds is consistent with the UPH, which posits a (possibly universal) stage of grammatical development characterized by the presence of an underspecified Place category associated with basic locative semantics.

Turning now to the role of lexical properties in acquisition, the results of our corpus study (Study 2) showed that the child's use of strong prepositions with IN and ON semantics is not significantly different from that of the adults, whereas her use of weak

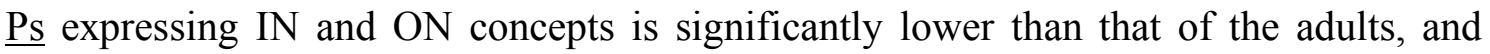
moreover, strongly correlates with age. Specifically, the child's use of weak Ps becomes more adult-like towards the end of the corpus. This conclusion is also consistent with the pattern observed for the use of strong and weak Ps by the two-year-old participants of Study 1 (see above).

Given these results, we can assess the relative importance of several factors potentially influencing the acquisition rate of locative prepositions: conceptual hierarchy, frequency, morphological complexity, semantic ambiguity, phonological strength, and lexical diversity. Recall that these factors make contrasting predictions with respect to Norwegian. The conceptual hierarchy proposed by Johnston and Slobin (1979) predicts that Norwegian items with IN, ON and UNDER semantics should be acquired before items representing more complex concepts, such as BEHIND. This prediction is consistent with the corpus data: As shown above, Ina first uses bak 'behind' in file 14 
(age 2;6), whereas she starts using items expressing IN, ON and UNDER already from the beginning of the corpus, before age 2;0. The adults use locative items for all of the four locative concepts consistently throughout the corpus. ${ }^{4}$ However, the conceptual hierarchy does not explain the observed difference in the acquisition rate of strong and weak IN and ON prepositions, specifically that strong versions of IN and $\mathrm{ON}$ are acquired earlier than their weak counterparts.

Next, if the crucial factors influencing the rate of $\mathrm{P}$ acquisition are frequency and/or morphological complexity, it is expected that the morphologically simple and highly frequent weak IN and ON prepositions should be acquired before their strong counterparts, which are morphologically complex and less frequent in the input. These predictions are not consistent with our results: the use of morphologically complex and less frequent strong Ps becomes target-like significantly earlier than that of their weak counterparts. This suggests that if frequency and morphological complexity indeed have an impact on the rate of $\mathrm{P}$ acquisition, their influence is overridden by other factors.

We then move on to the prediction that items that can carry stress and are unambiguously locative in meaning (strong Ps) would be acquired prior to items that are unstressed and highly ambiguous (weak Ps). This prediction was corroborated by the results of the between-subject elicited production experiment (Study 1) and by the longitudinal corpus study (Study 2). We may thus conclude that phonological strength and/or the lack of semantic ambiguity play a decisive role in facilitating the acquisition of locative items in Norwegian.

In order to assess the influence of lexical diversity on the acquisition of locative items,

\footnotetext{
${ }^{4}$ Admittedly, the frequency of $b a k$ 'behind' in our corpus is very low: Ina only uses this item 5 times, while the adults use it 38 times throughout the corpus. The sparse amount of data does not allow for a statistical analysis, and we leave further investigation of this issue for future research.
} 
we can compare the rate of preposition omission in the responses of Russian and Norwegian two-year-olds. Recall that Johnston and Slobin (1979) speculated that lexical diversity might be a factor negatively influencing the rate of $\mathrm{P}$ acquisition. If this is the case, we expect locative items expressing IN and ON to appear earlier in the speech of Russian children than in the speech of their Norwegian peers, given the fact that each of these concepts is expressed by a single preposition in Russian, while there are multiple items expressing these concepts in Norwegian. However, this prediction is not borne out: Russian children do not master IN and ON prepositions earlier than their Norwegian peers, and the rate of overt IN and ON prepositions is higher in the speech of Norwegian twoyear-olds than in the responses of the Russian children $(20 \%$ bare $\mathrm{N}$ responses for the IN/ON configurations in the Norwegian group vs. $28 \%$ bare $\mathrm{N}$ responses for the Russian group, as calculated based on the dataset presented in Mitrofanova 2017). We hypothesize that the difference in the rate of preposition omission between Norwegian and Russian children may be attributed to the fact that only Norwegian has phonologically strong and semantically unambiguous locative items. As we have argued, phonological salience and/or semantic unambiguity are important factors facilitating $\mathrm{P}$ acquisition. Thus, Norwegian strong Ps are expected to appear earlier in production than their phonologically weak and semantically ambiguous Russian counterparts, leading to a slightly lower rate of preposition omission in early Norwegian. Another factor potentially contributing to the prevalence of preposition omission in Russian early locative utterances, as compared to Norwegian, is the presence of overt case marking on complement DPs (recall that the Russian children predominantly use prepositional case across all utterances involving preposition omission). Mitrofanova (2017) argues that locative case marking in Russian may initially be interpreted by children as an overt realization of the underspecified Place head. Norwegian does not overtly express case, thus there is no 
functional morpheme that can be analyzed as the overt realization of the underspecified Place node. For this reason, Norwegian children may experience a greater pressure to acquire items realizing locative semantics as compared to Russian children.

Table 7 summarizes the predictions based on the six factors discussed above, and evaluates them in light of the results of our study.

TABLE 7. Evaluation of the predictions

\begin{tabular}{l|l|l}
\hline Factor & Prediction & Evaluation \\
\hline Conceptual hierarchy & IN, ON, UNDER > BEHIND & corroborated \\
Overall frequency & weak > strong (for IN and ON) & not corroborated \\
Morphological complexity & weak > strong (for IN and ON) & not corroborated \\
$\begin{array}{l}\text { Semantic ambiguity / } \\
\text { Phonological strength }\end{array}$ & strong > weak & corroborated \\
Lexical diversity & Russian > Norwegian & not corroborated \\
\hline
\end{tabular}

To sum up, our results for Norwegian indicate that phonological salience and/or the lack of semantic ambiguity may significantly facilitate lexical learning of locative items in Norwegian, while factors such as overall frequency, morphological complexity and lexical diversity play a less important role.

Study 1 also revealed an unexpectedly large proportion of utterances containing strong prepositions without complements (bare strong Ps) in the responses of all groups of children (see Fig 5 above). As already discussed, despite its low overall frequency, the bare strong $\mathrm{P}$ construction is not ungrammatical in Norwegian; nevertheless, children of all age groups produced this construction significantly more often in our experiment as compared to the adult controls. Note that the omission of complements with strong Ps as observed in Study 1 is not correlated with preposition omission. No significant difference was observed between two-, three- and four-to-five-year-olds with respect to the 
proportion of utterances involving bare strong Ps. Bare N utterances, on the other hand, were predominantly observed in the responses of the two-year-olds, only marginally present in the responses of the three-year-olds and completely absent from the speech of the four-to-five-year-olds. Given the UPH, we have argued that preposition omission in the speech of Russian and Norwegian two-year-olds reflects a difference in grammatical representation, where children initially postulate only one underspecified Place head with further contrasts evolving incrementally, based on the acquisition of individual locative items. The high rate of bare strong P utterances in the speech of Norwegian pre-school children is of a different nature and is arguably not the result of a discrepancy in grammatical knowledge between children and adults.

A number of studies have argued that certain types of omission in children's production should be primarily attributed to performance issues, rather than to the lack of grammatical competence. In a discussion of null subjects in child speech, Rizzi (2005) argues that early subject drop may be used to alleviate an immaturity in the production system and suggests that "language development is grammatically based, but performance driven" (p.102). Similarly, Philips (2010) argues that "particular errors of omission are better explained by a problem the children have in the implementation of certain aspects of $\ldots$ <grammatical $>$ knowledge", and not by a deficit in that knowledge (p.133). Omissions and lack of syntactic movement in L1 acquisition of Norwegian have also been attributed to a general economy principle in child language (see e.g., Westergaard 2008, 2009, 2016). Following this line of research, we suggest that the higher rate of bare strong Ps in the responses of Norwegian children as compared to the adults does not reflect a fundamental structural difference between child and adult grammars. Instead, it may be attributed to factors outside of grammar proper, e.g., the economy of effort in production (cf. Philips 2010). 
In the follow-up experiment to Study 1 we tested whether the rate of bare $\mathrm{P}$ utterances would decrease in a different pragmatic context, e.g., in a situation when the interlocutor could not retrieve the ground object from the visual context. The results confirmed that this was the case: the children were significantly more likely to supply overt ground complements in a situation where the ground object could not be retrieved by the interlocutor from the visual context. This supports our hypothesis that the nature of complement omission is not due to a difference in grammatical representations between children and adults, as the children are sensitive to the pragmatic context and able to produce full PPs in situations where they were pragmatically required.

To sum up, we propose that the high rate of bare strong $\mathrm{P}$ utterances in the responses of child participants in Study 1 as compared to the adults may be attributed to children's tendency to prefer more economic utterances over more informative ones. We leave a more in-depth investigation of the exact nature of the factors underlying this type of omission for future research.

\section{CONCLUSION}

In this paper, we have focused on the acquisition of locative utterances in L1 Norwegian in two separate studies, an elicited production study and a corpus study. Study 1 elicited a variety of locative utterances from monolingual Norwegian children aged 2-5, and the results were compared to a similar study conducted with Russian children (Mitrofanova, 2017). Norwegian two-year-olds were shown to omit prepositions, which is ungrammatical in the target grammar. In this respect, Norwegian two-year-olds pattern with their Russian peers. The use of bare N(oun) locatives decreases rapidly and becomes truly marginal by the age of three in both Norwegian and Russian. This is in line with the Underspecified P(lace) Hypothesis (UPH; Mitrofanova, 2017), which posits a stage of grammatical development characterized by the presence of a phonologically null and 
semantically underspecified Place category associated with basic locative semantics.

We further examined the role of the following factors in determining the rate of acquisition of individual locative Ps in Norwegian: conceptual hierarchy, overall frequency, morphological complexity, phonological strength, semantic ambiguity, and lexical diversity. Based on the results of Studies 1 and 2 we concluded that phonological strength and/or lack of semantic ambiguity are the major factors facilitating lexical learning of locative items, while overall frequency and morphological complexity play a less important role. Furthermore, a comparison between Russian and Norwegian did not reveal a significant effect of lexical diversity on the acquisition rate of locative prepositions.

A result that was not predicted by the UPH was a significantly larger proportion of responses involving phonologically strong prepositions produced in isolation (i.e., bare strong Ps), observed for all age groups of Norwegian children as compared to the adult controls. We suggest that this pattern should be attributed to factors outside of grammar proper, e.g., the economy of effort in production (cf. Philips 2010; Rizzi 2005; Westergaard 2008, 2016). A follow-up experiment which involved a change in the pragmatic context (the experimenter could not see the picture that the child was describing) revealed a significant decrease of bare P utterances in the children's responses, indicating that children preferred more economic utterances in situations where the omitted element could be retrieved from the context. 


\section{REFERENCES}

Ambridge, B. (2010). Frequency effects in language acquisition: Defining the limits of frequency as an explanatory concept Journal of Child Language 37, 453-460.

Ambridge, B, Kidd, E., Rowland, C. F., \& Theakston, A. L. (2015). The ubiquity of frequency effects in first language acquisition. 42(2), 239-273.

Anderssen, M. (2005). The acquisition of compositional definiteness in Norwegian. Doctoral Dissertation. University of Tromsø.

Anderssen, M., \& Westergaard, M. (2010). Frequency and economy in the acquisition of variable word order. Lingua, 120(11), 2569-2588.

Bates, D., Mächler, M., Bolker, B., M., \& Walker, S., C. (2014). Fitting Linear MixedEffects Models using lme4. Journal of Statistical Software.

Bowerman, M. (1973). Early syntactic development: a cross-linguistic study with special reference to Finnish. Cambridge: Cambridge University Press.

Brown, R. (1973). A first language: the early stages. Cambridge, Mass: Harvard University Press.

Caha, P. (2009). The nanosyntax of case. PhD dissertation. University of Tromsø, Tromsø.

Casasola, M. and Cohen, L. (2002). Infant categorization of containment, support and tight-fit spatial relationships. Developmental Science 5, 247-264.

Caselli, C., Casadio, P., \& Bates, E. (1999). A Comparison of the Transition from First Words to Grammar in English and Italian. Journal of Child Language, 26(1), 69111.

Clahsen, H. (1990). Constraints on Parameter Setting: A Grammatical Analysis of Some Acquisition Stages in German Child Language. Language Acquisition, 1(4), 361-391.

Clahsen, H., \& Penke, M. (1992). The Acquisition of Agreement Morphology and its Syntactic Consequences: New Evidence on German Child Language from the Simone-Corpus. In J. Meisel (Ed.), The Acquisition of Verb Placement. Vol. 16. Netherlands: Springer.

Clahsen, H., Eisenbeiss, S., \& Penke, M. (1996). Lexical Learning in Early Syntactic Development. In H. Clahsen (Ed.), Generative Perspectives on Language Acquisition: Empirical findings, theoretical considerations and crosslinguistic comparisons. Vol. 14. Amsterdam: Benjamins. 
Clahsen, H., Eisenbeiss, S., \& Vainikka, A. (1994). The seeds of structure: a syntactic analysis of the acquisition of case marking. In T. Hoekstra \& B. Schwartz, D. (Eds.), Language Acquisition Studies in Generative Grammar. Vol. 8. Amsterdam: Benjamins.

Clark, E. V. (1973). What's in a word? On the child's acquisition of semantics in his first language. In T. E. Moore (Ed.) Cognitive Development and Acquisition of Language. New York: Academic Press.

Clark, E. V. (1977). Strategies and the mapping problem in first language acquisition. In J. Macnamara (Ed.) Language learning and thought. New York: Academic Press.

Duffield, N. (2008). Roots and Rogues in German Child Language. Language Acquisition, 15(4), 225-269.

Eisenbeiss, S. (2009). Contrast is the Name of the Game: Contrast-Based SemiStructured Elicitation Techniques for Studies on Children's Language Acquisition. Essex Research Reports in Linguistics 57 (7)

Eisenbeiss, S. (2010). Production Methods. In E. Blom \& S. Unsworth (Eds.), Experimental Methods in Language Acquisition Research. Amsterdam: John Benjamins.

Felix, S. (1992). Language acquisition as a maturational process. In J. Weissenborn, H. Goodluck \& R. Roeper (Eds), Theoretical issues in language acquisition. Lawrence Erlbaum.

Gagarina, N., \& Voeikova, M. (2009). Acquisition of Case and Number in Russian. In U. Stephany \& M. Voeikova (Eds.), Development of Nominal Inflection in First Language Acquisition: A Cross-Linguistic Perspective. Berlin, Germany: Mouton de Gruyter.

Gibson, E. J., \& Spelke, E. S. (1983). The development of perception. In P. H. Mussen, (Ed.) Handbook of Child Psychology, Vol. 3: Cognitive Development. New York: Wiley.

Gleitman, L. R., \& Wanner, E. (1982). Language acquisition: the state of the art. Cambridge: Cambridge University Press.

Gülzow, I. \& Gagarina, N. (2007). Frequency effects in language acquisition: defining the limits of frequency as an explanatory concept. Berlin: Mouton de Gruyter. 
Jaeger, T. F. (2008). Categorical Data Analysis: Away from ANOVAs (Transformation or Not) and towards Logit Mixed Models. Journal of Memory and Language, 59(4), 434-446.

Johnston, J. R., \& Slobin, D. I. (1979). The Development of Locative Expressions in English, Italian, Serbo-Croatian and Turkish. Journal of Child Language, 6(3), 529-545.

Kern, S., Gayraud, F., \& Chenu, F. (2014). The role of input in early first language morphosyntactic development. LIA Language, Interaction and Acquisition, 5(1), $1-18$.

Koopman, H. (2000). Prepositions, postpositions, circumpositions, and particles In The Syntax of Specifiers and Heads. Collected Essays of Hilda J. Koopman. London: Routledge.

Lakusta, L., Wagner, L., O’Hearn, K., \& Landau, B. 2007. Conceptual foundations of spatial language: Evidence for a goal bias in infants. Language Learning and Development, 3: 179-197.

Leikin, M. (1998). Acquisition of Locative Prepositions in Russian. Journal of Psycholinguistic Research, 27(1), 91-108.

Lieven, E. (2010). Input and first language acquisition: Evaluating the role of frequency. Lingua, 120(11), 2546-2556.

MacWhinney, B. (2000). The CHILDES project: tools for analyzing talk (2nd ed. ed.). Hillsdale, N.J: L. Erlbaum.

Mandler, J. M. (1996). Preverbal representation and language. In P. Bloom, M. A. Peterson, L. Nadel, \& M. F. Garrett (Eds.) Language and Space. Cambridge, MA: MIT Press.

Mandler, J. M. (2004). The foundations of mind: Origins of conceptual thought. New York: Oxford University Press.

Mitrofanova, N. (2017). Early underspecification of functional categories: Evidence from the acquisition of locative PPs in Russian. Language Acquisition: A Journal of Developmental Linguistics.

Nelson, K. (1974). Structure and strategy in learning to talk. Monograph of the Society for Research in Child Development, 38, no. 149.

Nicholas, K. E. (2011). Children's omission of prepositions in English and Icelandic. (PhD), University of Arizona. 
Phillips, C. (2010). Syntax at Age Two: Cross-Linguistic Differences. Language Acquisition, 17(1-2), 70-120.

Piaget, J., \& Inhelder, B. (1956). The child's conception of space. London: Routledge \& Kegan Paul.

Pulverman R., J. L. Sootsman, R. M. Golinkoff, \& K. Hirsh-Pasek. (2002). Infants' non-linguistic processing of motion events: one-year-old English speakers are interested in manner. In E. V. Clark (Ed.) Space in Language -Location, Motion, Path, and Manner. 31st Stanford Child Language Research Forum, Stanford: CSLI Publications.

Quené, H., \& Bergh, H. v. d. (2008). Examples of Mixed-Effects Modeling with Crossed Random Effects and with Binomial Data. Journal of Memory and Language, 59(4), 413-425.

Quinn, P. C. (1994). The Categorization of Above and Below Spatial Relations by Young Infants. Child Development, 65(1), 58-69.

Quinn, P. C., Norris, C. M., Pasko, R. N., Schmader, T. M., \& Mash, C. (1999). Formation of a Categorical Representation for the Spatial Relation Between by 6to 7-month-old Infants. Visual Cognition, 6(5), 569-585.

Radford, A. \& Ramos, E. (2001). Case, Agreement and EPP: Evidence from an English-speaking child with SLI. Essex Research Reports in Linguistics.

Rizzi, L. (2005). On the Grammatical Basis of Language Development: A Case Study. In G. Cinque \& R. Kayne (Eds.), The Oxford Handbook of Comparative Syntax. Oxford and New York: Oxford University Press.

Slobin, D. I. (1985). The Crosslinguistic study of language acquisition : 1 : The data. Vol. 1. Hillsdale, N.J: Lawrence Erlbaum.

Svenonius, P. (2006). The Emergence of Axial Parts. Nordlyd, 33(1), 49-77.

Svenonius, P. (2010). Spatial P in English. In G. Cinque \& L. Rizzi (Eds.), Mapping Spatial PPs: The Cartography of Syntactic Structures: Oxford University Press. Svenonius, P. (2012). Spanning. Ms. CASTL, University of Tromsø.

Talmy, L. (2000). Toward a cognitive semantics: Vol. 1: Concept structuring systems. Cambridge, Mass: MIT Press.

Taraldsen, K. T., \& Svenonius, P. (2007). The construct state in Norwegian prepositional phrases, Ms. University of Tromsø. 
Theakston, A. L., Lieven, E. V. M., Pine, J. M., \& Rowland, C. F. (2004). Semantic Generality, Input Frequency, and the Acquisition of Syntax. Journal of Child Language, 31(1), 61-99.

Tomasello, M. (1987). Learning to use prepositions: a case study. Journal of Child Language, 14(1), 79-98.

Wagner, L., \& S. Carey. (2005). Twelve-month-old infants represent probable endings of motion events. Infancy 7: 73-83.

Westergaard, M. (2008). Verb Movement and Subject Placement in the Acquisition of Word Order: Pragmatics or Structural Economy? In P. Guijarro-Fuentes, P. Larranaga \& J. Clibbens (eds.), First Language Acquisition of Morphology and Syntax: Perspectives across languages and learners. [Language Acquisition and Language Disorders 45]. Amsterdam: John Benjamins.

Westergaard, M. (2009). The Acquisition of Word Order: Micro-cues, Information Structure and Economy. [Linguistik Aktuell/Linguistics Today 145], Amsterdam: John Benjamins.

Westergaard, M. (2016). Word order and finiteness in acquisition: A study of English and Norwegian wh-questions. In K. M. Eide (Ed.), Finiteness matters. On finiteness-related phenomena in natural language. Amsterdam: John Benjamins. 
APPENDIX. DETAILS OF THE STATISTICAL ANALYSIS

\section{Experiment 1}

TABLE 8

Fixed effects for Model 1 (the probability of bare N; Age: 2-year-olds and

Configuration: IN\&ON as baseline)

Estimates (Std.error)

\begin{tabular}{ll}
\hline (Intercept) & $-2.00(0.72)^{* *}$ \\
AgeGroup & \\
$\quad$ 3-year-olds & $-4.62(1.21)^{* * *}$ \\
Configuration & \\
$\quad$ UNDER\&BEHIND & $-0.73(0.61)$ \\
Age(3-year-olds) * Configuration(UNDER\&BEHIND) & $1.55(0.90)$
\end{tabular}

Significance codes: $* p<.05 * * p<.01 * * * p<.001$

TABLE 9

Fixed effects for Models 2 and 3 (the probability of full PPs and bare strong Ps; 2-yearolds in the IN\&ON configuration taken as baseline)

\begin{tabular}{lll}
\hline & $\begin{array}{l}\text { full PPs } \\
\text { Estimates (SE) }\end{array}$ & $\begin{array}{l}\text { bare strong Ps } \\
\text { Estimates (SE) }\end{array}$ \\
\hline (Intercept) & $-0.59(0.38)$ & $-2.12(0.38)^{* * *}$ \\
Age & & \\
$\quad$ adults & $4.38(0.68)^{* * *}$ & $-1.87(0.70)^{* *}$ \\
$\quad$ 3-year-olds & $2.00(0.44)^{* * *}$ & $-0.21(0.45)$ \\
$\quad$ 4-year-olds & $1.96(0.55)^{* * *}$ & $0.07(0.54)$ \\
$\quad$ 5-year-olds & $3.34(0.63)^{* * *}$ & $-0.84(0.63)$ \\
Configuration & & \\
$\quad$ UNDER\&BEHIND & $-1.12(0.39)$ & $0.72(0.41)$ \\
Age (adults)*Config(U\&B) & $-1.75(0.59)^{* *}$ & $-0.31(0.73)$ \\
Age (3-years)*Config(U\&B) & $-0.35(0.35)$ & $0.03(0.42)$ \\
Age (4-years)* Config(U\&B) & $-0.86(0.43)^{*}$ & $0.44(0.49)$ \\
Age (5-years)* Config(U\&B) & $-1.57(0.50)^{* *}$ & $1.13(0.57)^{*}$ \\
\hline
\end{tabular}

Significance codes: $* p<.05 * * p<.01 * * * p<.001$ 


\section{Follow-up experiment (puzzle-board task)}

TABLE 10.

Participants' demographics by age group, follow-up experiment (puzzle-board task)

\begin{tabular}{cccc}
\hline Age group & $N$ & Age range & Mean age \\
\hline 2-year-olds & 3 & $2 ; 2$ to $2 ; 5$ & $2 ; 4$ \\
3-year-olds & 5 & $3 ; 0$ to $3 ; 11$ & $3 ; 5$ \\
4-year-olds & 4 & $4 ; 2$ to $4 ; 9$ & $4 ; 5$ \\
5-year-olds & 5 & $5 ; 5$ to $5 ; 11$ & $5 ; 8$ \\
\hline
\end{tabular}

\section{TABLE 11}

Fixed effects for Model 4 (the probability of bare strong $P$ responses; Experiment 1 (picture book) as baseline)

\section{Estimates (Std.error)}

\begin{tabular}{ll}
\hline (Intercept) & $-2.28(0.49)^{* * *}$ \\
Experiment (puzzle board) & $-1.48(0.68)^{*}$
\end{tabular}

Significance codes: $* p<.05 * * p<.01 * * * p<.001$

\section{Corpus study}

\section{TABLE 12}

Fixed effects for Models 5 and 6 (the probability of strong $P$ and weak P uses; INA at the beginning of the corpus as baseline)

\begin{tabular}{|c|c|c|}
\hline & strong $\mathrm{P}$ uses & weak P uses \\
\hline & Estimates (SE) & Estimates (SE) \\
\hline (Intercept) & $-5.25(0.41)^{* * *}$ & $-5.95(0.24)^{* * *}$ \\
\hline \multicolumn{3}{|l|}{ Speaker } \\
\hline Adult & $-0.21(0.51)$ & $2.29(0.26)$ \\
\hline Age_in_months & $-0.00(0.01)$ & $0.06(0.01)^{* * *}$ \\
\hline Speaker(Adult)*Age_in_months & $-0.01(0.02)$ & $-0.06(0.01)^{* * *}$ \\
\hline
\end{tabular}

Significance codes: $* p<.05 * * p<.01 * * * p<.001$ 
TABLE 13

Fixed effects for Models 7 and 8 (the probability of locative and non-locative uses of weak Ps for INA)

\begin{tabular}{lll}
\hline & $\begin{array}{l}\text { locative uses } \\
\text { Estimates (SE) }\end{array}$ & $\begin{array}{l}\text { non-locative uses } \\
\text { Estimates (SE) }\end{array}$ \\
\hline (Intercept) & $-7.86(0.44)^{* * *}$ & $-5.99(0.29)^{* * *}$ \\
Age_in_months & $0.08(0.01)^{* * *}$ & $0.05(0.01)^{* * *}$ \\
\hline
\end{tabular}

Significance codes: $* p<.05 * * p<.01 * * * p<.001$ 